\title{
Microstructure and properties of NiCrBSiC overlay coatings deposited by the plasma scanning process
}

\author{
T. Simeonova ${ }^{1}$, M. Tongov ${ }^{1} \&$ G. Avdeev ${ }^{2}$ \\ ${ }^{1}$ Department of Materials Science and Technology, \\ Technical University - Sofia, Bulgaria \\ ${ }^{2}$ Institute of Physical Chemistry, Bulgarian Academy of Science, Bulgaria
}

\begin{abstract}
NiCrBSiC coatings on S275JR non-alloy structural steel substrate were produced using the plasma transferred arc (PTA) scanning process. Coatings were carried out by a preplaced powder method using a mixture of $\mathrm{NiCrBSiC}$ powder and a binder, painted over the substrate. The thickness of the coatings ranged from 1 to $2.5 \mathrm{~mm}$ due to the use of three different current densities (50,65 and $80 \mathrm{~A}$ ). Layers were produced under Ar atmosphere and cooled in air. Microstructural characterization studies were carried out by optical and scanning electron microscopy (SEM), X-ray diffraction (XRD) and microhardness measurements. They revealed the presence of a $\gamma-\mathrm{Ni}$ solid solution dendritic phase and interdendritic precipitates, which were found to be $\mathrm{Ni}_{3} \mathrm{~B}$ and $\mathrm{Cr}_{23} \mathrm{C}_{6}$ particles. It is determined that the thickness of the coating layer increases with the current density and the concentration of the alloying elements decreases. Coatings are homogenous and no cracks or pores were detected in the interface. The hardness of layers varies in the range of 400-1800 HK.

Keywords: NiCrBSiC coating, PTA scanning process, microstructure, hardness, overlaying.
\end{abstract}

\section{Introduction}

In recent years, a lot of investigations considering different surfacing techniques were carried out in order to improve the surface properties of materials. Most of these techniques involve high concentrated energy sources for producing coatings with fine microstructure and enhanced mechanical and tribological 
properties without seriously affecting the properties of the substrate material. In this respect there has been considerable interest in the use of $\mathrm{NiCrBSi}$ powders with different overlaying methods such as plasma spraying [1-3], High Velocity Oxygen Fuel (HVOF) spraying [4, 5], flame spraying [6-9], laser cladding [612] and plasma transferred arc processes [12-18]. Among these processes PTA surfacing process is characterized by extremely high temperature, excellent arc stability, low thermal distortion of the part, and high coating speeds and so it is widely used for the surface treatment of materials. Zikin et al. [14] has made advanced chromium carbide-based hardfacing by PTA process and reported that the original NiCrBSi matrix alloy has indicated a high amount of $\mathrm{FeNi}_{3}$ solid solution in Ni-based matrix with presence of small amount of $\mathrm{Ni}_{3} \mathrm{~B}$ and $\mathrm{Cr}_{7} \mathrm{C}_{3}$ hard phases. When 40 vol. $\% \mathrm{Cr}_{3} \mathrm{C}_{2}$ particles were added to the NiCrBSi alloy, $\mathrm{Cr}_{3} \mathrm{C}_{2}, \mathrm{Cr}_{7} \mathrm{C}_{3}$ and $\mathrm{M}_{23} \mathrm{C}_{6}$ phases could be detected by XRD analysis in the hardfaced layer [14]. Flores et al. [15] have investigated PTAW deposits obtained by two NiCrBSi alloys with differing $\mathrm{Cr}$ contents (from 10 to 12\%), which consisted of a $\gamma-\mathrm{Ni}$ dendritic phase and interdendritic precipitates which were found to be a boron-rich dark blocky phase, elongated $\mathrm{C}$ and $\mathrm{Cr}$-rich phase (Cr-carbide), and a $\mathrm{Cr}$ and B-rich flower-like phase (Cr-boride). Kesavan and Kamaraj [16] have reported that the as-deposited PTAW coating microstructure observed by TEM comprised carbides $\left(\mathrm{Cr}_{7} \mathrm{C}_{3}\right)$, borides $\left(\mathrm{Cr}_{2} \mathrm{~B}, \mathrm{CrB}\right)$ and silicides $\left(\mathrm{Ni}_{3} \mathrm{Si}\right)$ in $\gamma$-nickel matrix. In addition, microstructural characterization studies carried out by SEM and TEM revealed the coarsening of dendrites and precipitation of $\mathrm{Cr}_{23} \mathrm{C}_{6}$ particles in the same coatings after aging treatment [17]. Liyanage et al. [18] investigated the influence of alloy chemistry on microstructure and properties in $\mathrm{NiCrBSi}$ overlay coatings deposited by plasma transferred arc welding (PTAW) and reported that the coatings consist of a $\gamma-\mathrm{Ni}$ primary dendritic phase with harder $\mathrm{Ni}+\mathrm{Ni}_{3} \mathrm{~B}$ or $\mathrm{Ni}+\mathrm{Ni}_{3} \mathrm{Si}$ eutectics and $\mathrm{Cr}$-based particles $\left(\mathrm{CrB}, \mathrm{Cr}_{3} \mathrm{C}_{2}\right.$, and $\left.\mathrm{Cr}_{7} \mathrm{C}_{3}\right)$ situated at the interdendritic regions. As it can be seen, only few investigations concern the use of plasma transferred arc overlaying with NiCrBSi powders, and none of them involve preplaced powder method.

In this context the aim of present work is to study the possibility of obtaining NiCrBSiC coatings on S275JR non-alloy structural steel substrate using preplaced powder method and subsequent plasma transferred arc (PTA) scanning process.

\section{Experimental procedure}

\subsection{Materials and PTA overlaying}

The analyzed $\mathrm{NiCrBSiC}$ coatings were carried out by preplaced powder method, where the filler material is pasted as slurry over the substrate and subsequent plasma transferred arc scanning. S275JR non-alloy structural steel plates of 100x100x4 $\mathrm{mm}$ in dimension were used as substrate material. The NiCrBSiC slurry was made by mixing $\mathrm{NiCrBSiC}$ powder (with particles size in a range of 45-180 $\mu \mathrm{m}$ ), which chemical composition is shown in table 1 , with a $20 \%$ sodium silicate solution in water as a binder. 
Table 1: NiCrBSiC powder weight (\%) composition.

\begin{tabular}{|c|c|c|c|c|c|c|}
\hline $\mathrm{Ni}$ & $\mathrm{Cr}$ & $\mathrm{B}$ & $\mathrm{Si}$ & $\mathrm{C}$ & $\mathrm{Fe}$ & $\mathrm{O}$ \\
\hline Balance & 14.95 & 3.18 & 4.40 & 0.75 & 4.0 & 0.025 \\
\hline
\end{tabular}

The plates were then covered with so prepared slurry and heated up to $90^{\circ} \mathrm{C}$ for $30 \mathrm{~min}$ in order to dry out the moisture. The resulting thickness of pasted filler material was about $1.3-1.5 \mathrm{~mm}$. The specimens were then mounted on a cooper plate and scanned with the plasma arc to melt the coating layer and the upper surface of the substrate forming metallurgical bond between them. Schematic drawing of the plasma transferred arc scanning process is presented in previous investigations [13]. Four different sets of experiments were done with varying main PTA scanning parameters (refer to table 2). The parameters of the process were chosen so as to provide sufficient thickness and formation of the coating layers. Overlays were produced under Ar atmosphere and cooled in air. All analyzed coatings were deposited in one pass.

Table 2: PTA scanning parameters.

\begin{tabular}{|l|c|c|c|c|}
\hline & PS 1.1 & PS 2.1 & PS 2.2 & PS 3.1 \\
\hline Scanning current, A & 65 & 50 & 50 & 80 \\
\hline Scanning speed, mm/min & 85 & 85 & 55 & 85 \\
\hline Lateral step, mm & 3 & 3 & 3 & 3 \\
\hline Plasma gas flow rate - Ar, 1/min & 0.8 & 0.8 & 0.8 & 0.8 \\
\hline Shield gas flow rate - Ar, 1/min & 5 & 5 & 5 & 5 \\
\hline
\end{tabular}

\subsection{Characterization}

Metallographic preparation of coated surfaces for examination involved preparing transverse sections by grinding and polishing up to $1 \mu \mathrm{m}$ diamond paste and then etching the specimens with $2 \% \mathrm{HNO}_{3}$ solution in ethanol. Overlay characterization included microstructural analysis on the transverse section of specimens by optical and scanning electron microscopy (SEM), using the secondary electron and backscattered imaging mode. Chemical composition identification of a certain points of overlaid coatings was performed in SEM by energy dispersive X-ray microanalysis (EDS). X-ray diffraction (XRD - using $\mathrm{Cu} \mathrm{K} \alpha$ radiation) analysis of the coatings was performed to evaluate phase changes associated with the deposition process. Knoop microhardness measurements with $50 \mathrm{~g}$ load were carried out on the transverse cross section of the deposits to assess the effect of processing parameters.

\section{Results and discussion}

\subsection{Visual inspection}

Four different layers were produced by changing the plasma arc current and scanning speed. Visual inspection of produced coatings showed that there is a 
poor formation of the layers deposited with 50A plasma arc current. As can be seen in Fig. 2(b) and (c) there are pores, unmelted regions and zones with lack of overlapping, even when scanning speed was decreased (PS 2.2 specimen). This led to the conclusion that used combination of process parameters is not good enough for producing satisfactory overlaying. With the use of higher currents (65 and 80A) these welding defects were avoid and typical formation of plasma transferred arc weld beads is observed, with $40 \%$ overlapping (Fig. 2(a) and (d)).

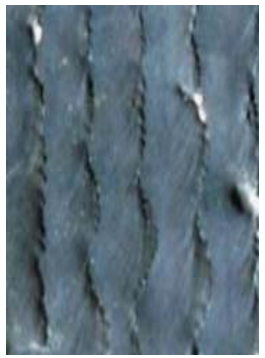

(a) PS 1.1

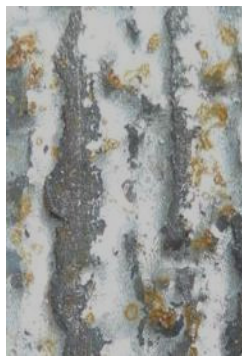

(b) PS 2.1

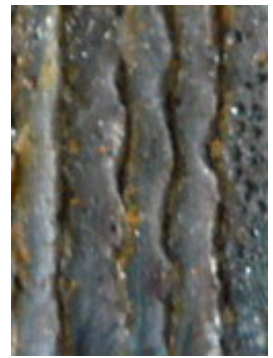

(c) PS 2.2

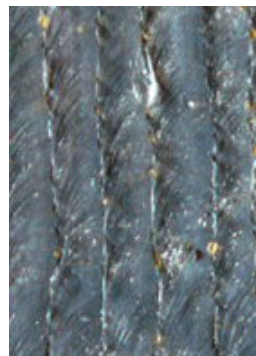

(d) PS 3.1

Figure 1: Layer formation.

\subsection{Microhardness properties}

To assess the properties of the layers, Knoop microhardness measurements with $50 \mathrm{~g}$ load were done and three hardness profiles were built for every layer. Profiles that consists highest hardness values are shown in Fig. 2 and average results from all profiles are presented in Fig. 3.

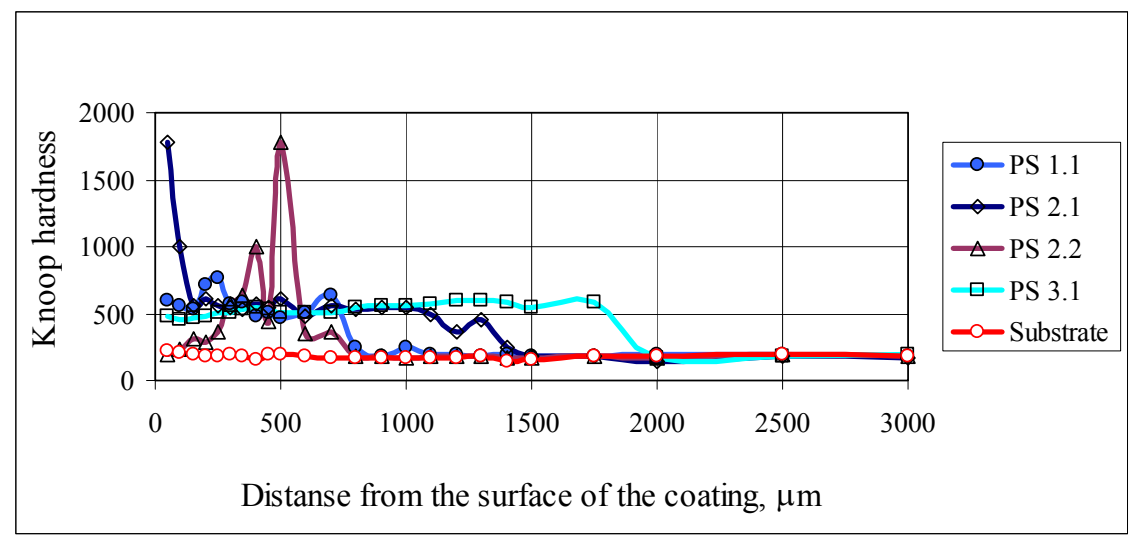

Figure 2: Profiles with highest hardness results.

It has to be pointed that 65A current layer (PS 1.1) has shown the best average hardness results of $500-600 \mathrm{HK}_{0.05}$, which are kept constant till 0.8 $0.9 \mathrm{~mm}$ dept from surface and then with assessing transition zone between 
coating and substrate the hardness lowered. The dept of the layer varies from 0.7 to $1.3 \mathrm{~mm}$ due to the typical formation of welding overlays. PS 2.1 and PS 2.2 layers, produced with 50A current, did not form homogenous coating and showed lower average hardness $\left(400-500 \mathrm{HK}_{0.05}\right.$ for PS 2.1 and $300-400 \mathrm{HK}_{0.05}$ for PS2.2), except for some zones, where the results of hardness measurements reached $1779 \mathrm{HK}_{0.05}$ (Fig. 3). Those huge variations in hardness results were probably due to the poor fusion of the filler powder with the substrate, which resulted in zones with higher concentration of hardening particles. PS 3.1 specimen differed from the other by the highest dept of the coating layer, which reached $2.5 \mathrm{~mm}$ while the other deposits were in a range of $0.7-1.5 \mathrm{~mm}$. The measured average hardness here varied from 400 to $600 \mathrm{HK}_{0.05}$. All these differences in the formation, hardness and thickness of the deposited layer are considered to be due to different currents and heat input that were used [12].

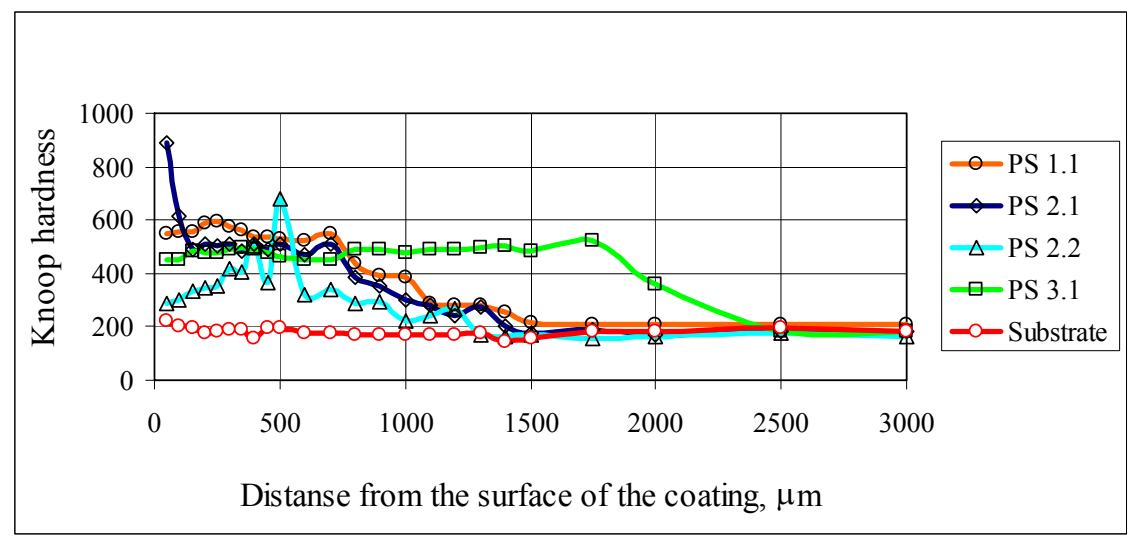

Figure 3: Average hardness of coatings.

\subsection{Microstructural analysis}

Microstructural examinations of the lower current coatings showed poor layer formation with a lot of welding defects, as it was mentioned before. Although the highest hardness values were measured on these specimens and that was the reason for them to be analyzed metallographicly. As can be seen, the whole layer is consisted of different hardening particles, which change their form from round in the transition zone to elongated one (Fig. 4). Despite that the presence of porosity and non-uniform formation of PS 2 series deposits led to the exclusion of these specimens from further characterization. For both elevated currents (65 and 80A) such welding defects were not observed.

Microstructure of the middle current layer is shown in Fig. 5. As it could be expected [14-18] it revealed a fine dendritic structure with the presence of hard phase precipitates in the interdendritic regions. It is assumed that increased heat input led to the melting of some hardening particles in a solid solution and to the uniform distribution of the rest. 


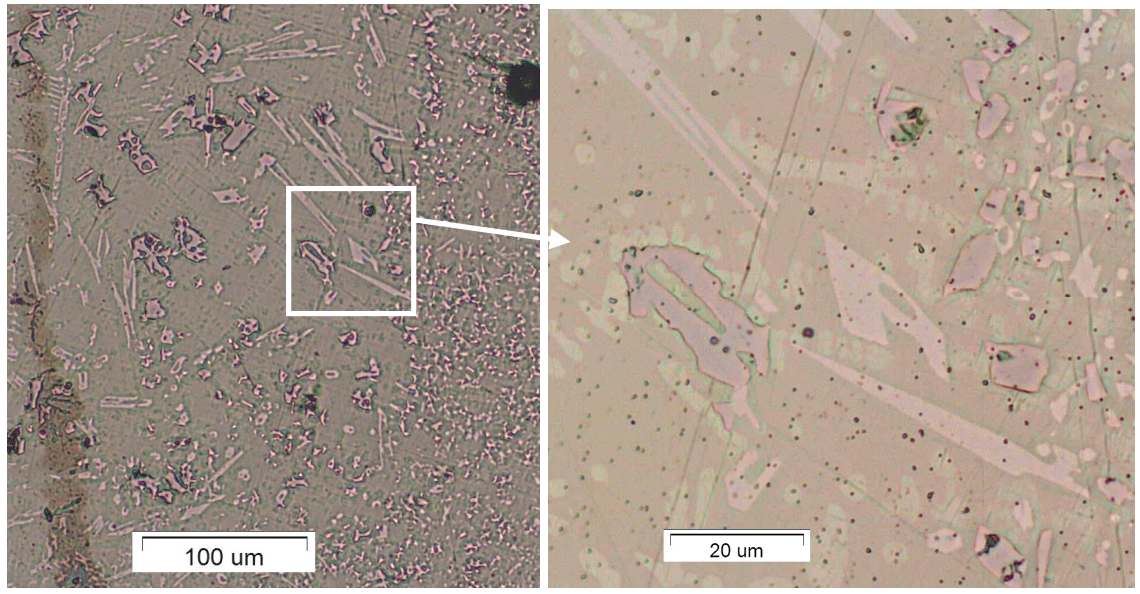

Figure 4: Microstructure of PS 2.1 layer.
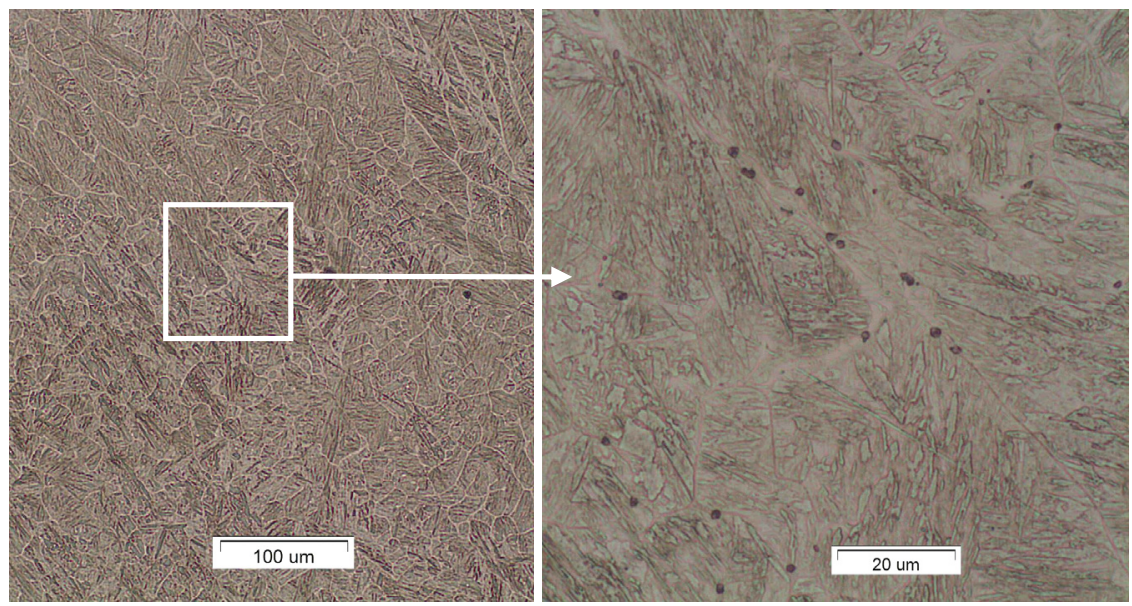

Figure 5: Microstructure of PS 1.1 layer.

Differences in shape precipitates can be observed in PS1.1 coating (Fig. 6). These particles are highly concentrated at the overlap areas and not so dense in layer matrix. On the base of literature research [14-16] it is believed that they are chromium carbides (light rounded and elongated particles) and nickel- or chrome-borides (dark round particles).

Microstructure of the higher current coating is showed in Fig. 7. It revealed the formation of a fine $\gamma-\mathrm{Ni}$ dendritic structure, typical for the crystallization processes in melted metals. Eutectics are formed in interdendritic regions, which most probably are based on a complex combination of borides and carbides [20]. 

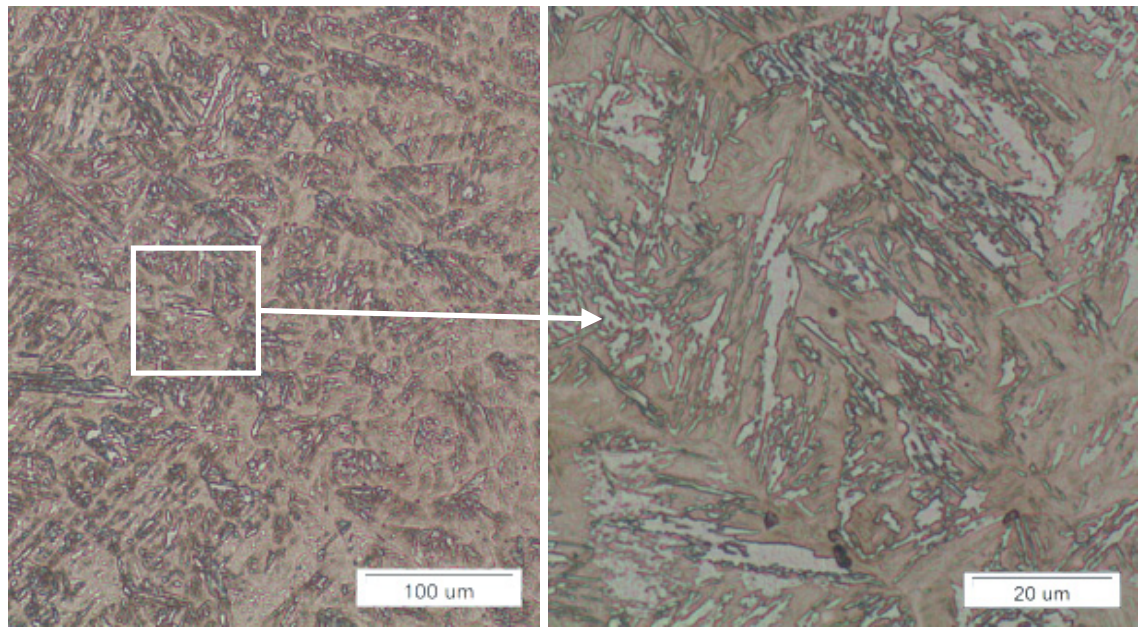

Figure 6: Overlapping zone in 65A current layer.
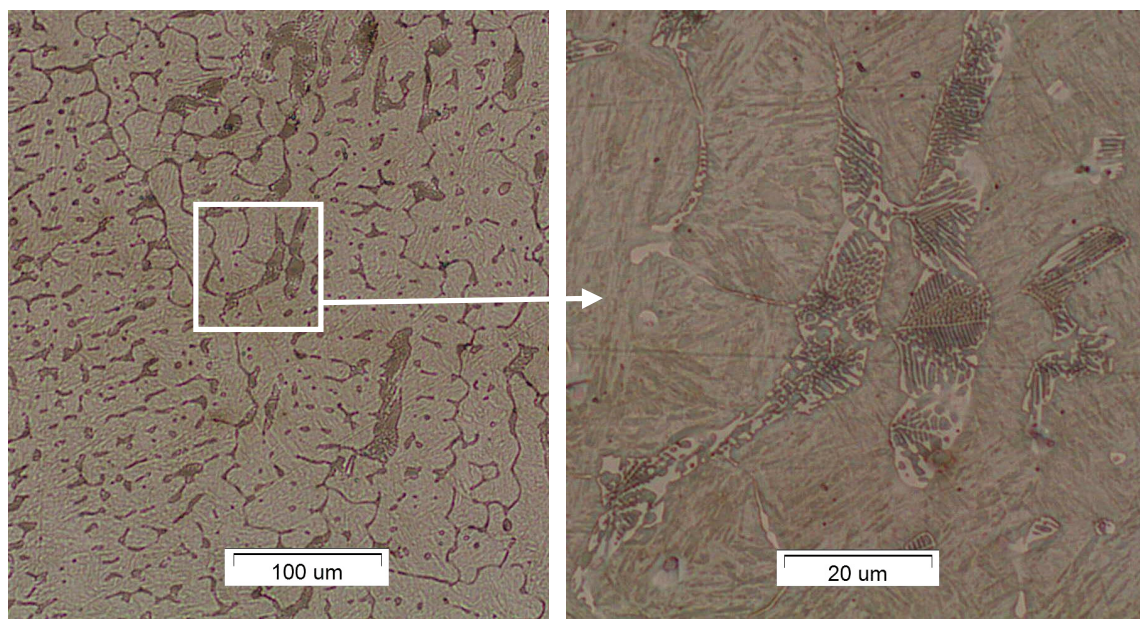

Figure 7: P.S 3.1 layer eutectics.

Except eutectics, in the layer is observed inhomogeneous distribution of carbides, with spherical, needle and elongated form (Fig. 5), but their concentration is lower than in other coatings.

\subsection{SEM and XRD analysis}

In order to reveal the chemical composition of a certain points in overlaid coatings an energy dispersive X-ray microanalysis (EDS) in SEM was performed. In addition X-ray diffraction (XRD) analysis of the coatings 
was performed to evaluate phase changes associated with the deposition process due to different currents. EDS analysis has shown that the matrix phase is a solid solution of $\mathrm{Ni}$ with some $\mathrm{Cr}$ and $\mathrm{Fe}$ and interdendritic phase is comprised mainly of $\mathrm{B}$ and $\mathrm{Cr}$ rich phases. Different in shape precipitates can be observed in the matrix by secondary electron and backscattered imaging mode (Figs 8-10).

The plotted B-rich points correspond to a phase with high amount of $\mathrm{B}, \mathrm{C}$ and some $\mathrm{Fe}$, which leads to the conclusion that boron carbides or complex $\mathrm{Fe}_{3}(\mathrm{C}, \mathrm{B})$ or $\mathrm{Fe}_{23}(\mathrm{C}, \mathrm{B})_{6}$ compound were formed. Furthermore the XRD analysis did not reveal the presence of $\mathrm{BC}_{4}$, so it is more likely $\mathrm{Fe}_{23}(\mathrm{C}, \mathrm{B})_{6}$ phase to be formed, especially when it's lattice has the same orientation as $\mathrm{Cr}_{23} \mathrm{C}_{6}$, which existence is proved. The plotted $\mathrm{Cr}$-rich points correspond to a phase with high amount of $\mathrm{Cr}, \mathrm{C}$ and $\mathrm{Fe}$, which leads to the conclusion that formation of chromium carbides $\left(\mathrm{Cr}_{7} \mathrm{C}_{3}\right.$ and $\left.\mathrm{Cr}_{23} \mathrm{C}_{6}\right)$ or complex $(\mathrm{Fe}, \mathrm{Cr})_{7} \mathrm{C}_{3}$ and $(\mathrm{Fe}, \mathrm{Cr})_{23} \mathrm{C}_{6}$ carbides is observed. In fact XRD analysis has proved the presence of these chromium carbides, which possess the same lattice orientation as the suggested complex carbides.
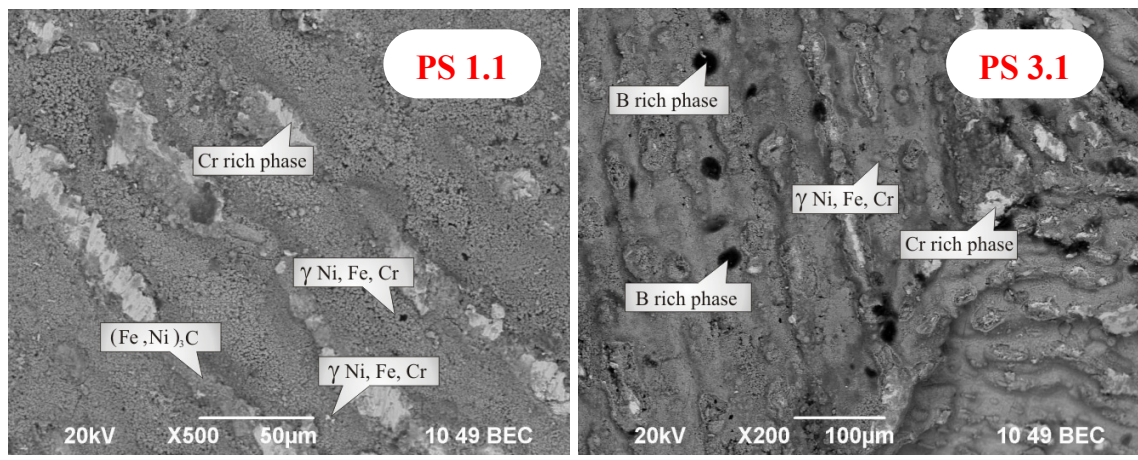

Figure 8: SEM images of PS 1.1 and PS 3.1 surfaces.
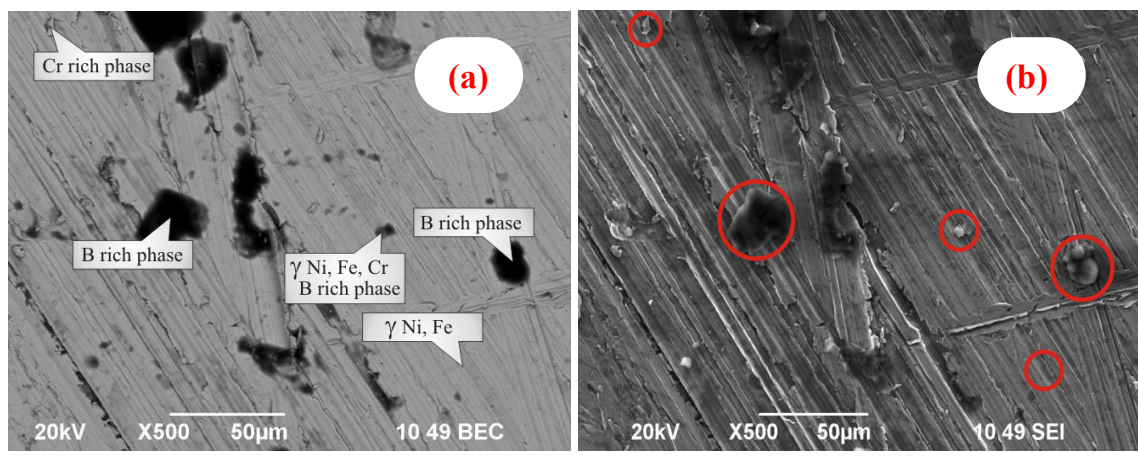

Figure 9: SEM images on PS 1.1 cross section. BEC (a) and SE (b) imaging mode. 

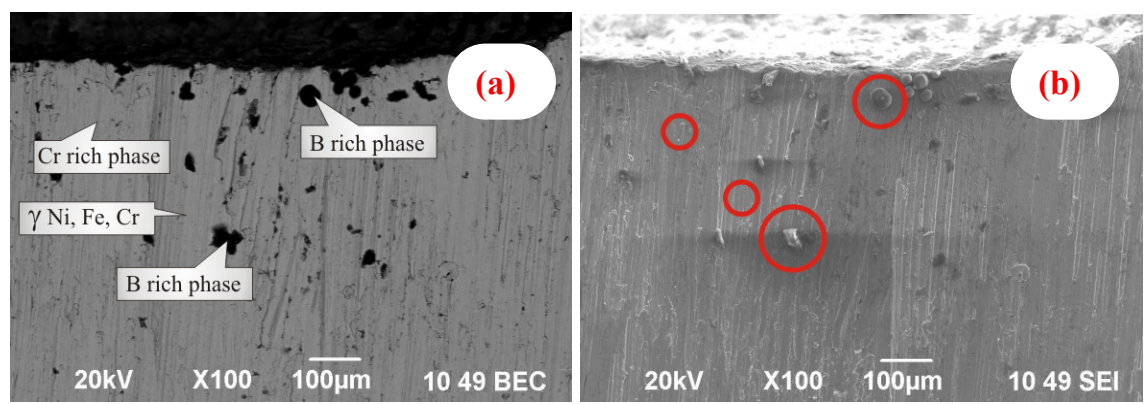

Figure 10: SEM images on PS 3.1 cross section. BEC (a) and SE (b) imaging mode.

The XRD diffraction patterns of PS 1.1, PS 3.1 coating surfaces and $\mathrm{NiCrBSiC}$ powder are shown in Fig. 11. The results for the layer, produced with 65 A current (PS 1.1), indicated the presence of $\mathrm{Ni}_{3} \mathrm{~B}, \mathrm{Cr}_{23} \mathrm{C}_{6}$ and some $\mathrm{Cr}_{7} \mathrm{C}_{6}$ hard phases. When employed arc current reached 80 A (PS 3.1 coating), the amount of $\mathrm{Ni}_{3} \mathrm{~B}, \mathrm{Cr}_{23} \mathrm{C}_{6}$ and $\mathrm{Cr}_{7} \mathrm{C}_{6}$ hard phases decreased (Fig. 11) probably due to the higher dilution and heat input, which led to the alloying of the hardening

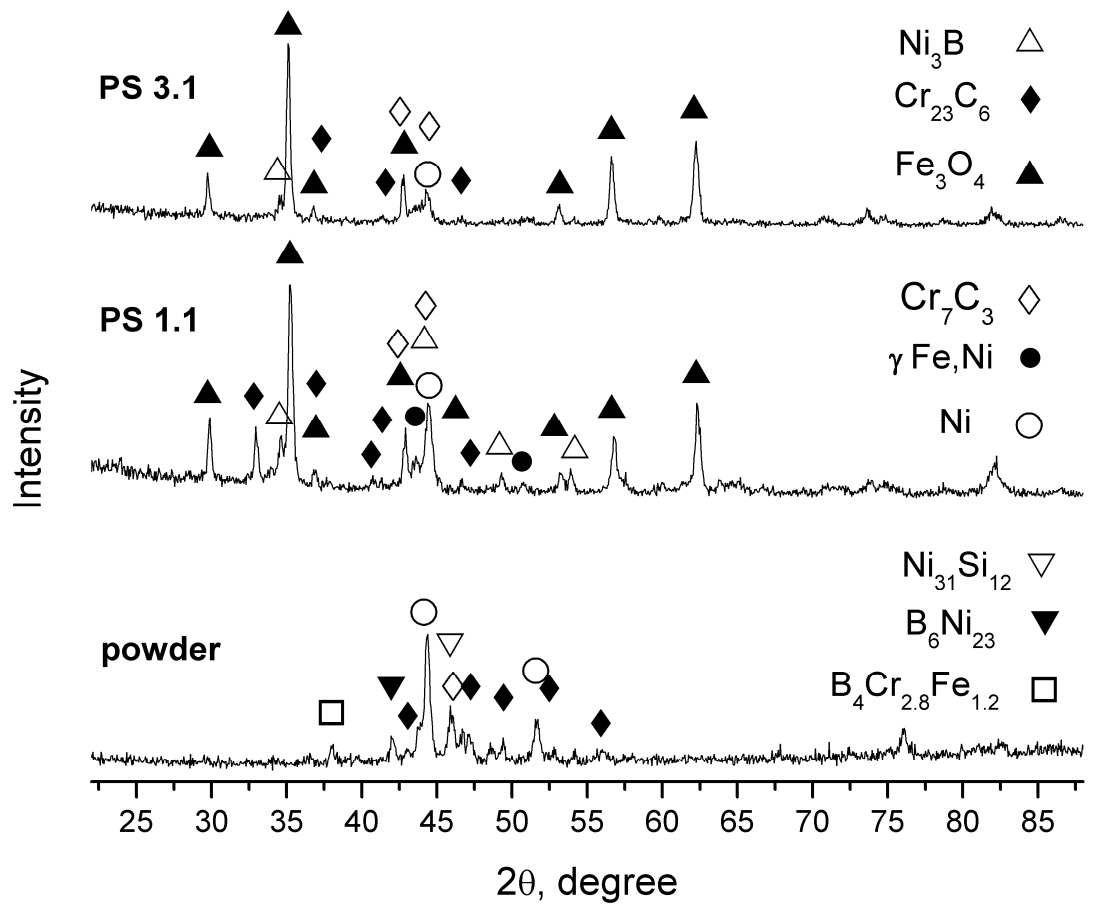

Figure 11: XRD diffraction patterns of PS 1.1, PS 3.1 coatings and $\mathrm{NiCrBSiC}$ powder. 
particles with the matrix. It should be outlined that XRD peaks for many chromium carbides and borides are very closely placed and with significant alloying in these phases, they could correspond to some complex carbides on a base of chromium, boron and iron or to some mixed Ni-Cr-Fe-B-C phase presented as precipitation in the matrix. It was also clearly shown that due to the cooling in air of both specimens a certain amount of $\mathrm{Fe}_{3} \mathrm{O}_{4}$ oxides are formed on the surface of the coatings.

\section{Conclusions}

A NiCrBSiC powder was successfully deposited on S275JR non-alloy structural steel substrate using preplaced powder method and subsequent PTA scanning process. The thickness of the layers increased with the increase of the plasma arc current density and varied from 1 to $2.5 \mathrm{~mm}$ in one pass. No crack or pores were observed in the coating layer and interface with the use of 65 and $80 \mathrm{~A}$ currents. Metallographic examinations on PS 1.1 deposit revealed a complex process of solid solution strengthening by melting some of the filler hard particles and immersing unmelted ones along the deposition thickness. In PS 3.1 coating most of the hardening particles are melted during solid solution strengthening process and thus a homogenous layer with enhanced hardness is obtained. As for the 50A current there were no sufficient results in layer formation which is considered to be a result of the unstable PTA scanning process. Due to the lower heat input in PS 2 series coatings a surface reinforcement is obtained by having the ceramic particles incorporated in the matrix of the layer. An average of 2.5 times increase in the hardness of the NiCrBSiC coatings was observed when compared to the substrate. The microhardness values vary in the range of $400-1800 \mathrm{HK}_{0.05}$ because of the microstructural complexity of plasma transferred arc $\mathrm{NiCrBSiC}$ coatings. The enhanced hardness of the coatings is attributed to the presence of uniformly distributed mixture of complex carbides and borides precipitate in $\gamma$ $\mathrm{Ni}$ solid solution matrix. These precipitates were identified as $\mathrm{Ni}_{3} \mathrm{~B}, \mathrm{Cr}_{23} \mathrm{C}_{6}$ and $\mathrm{Cr}_{7} \mathrm{C}_{6}$ by XRD analysis. It was also determined that the thickness of the coating layer increases with the current density and the concentration of the alloying elements decreases.

\section{Acknowledgements}

The research is related to project No BG051PO001-3.3.06-0046 "Development support of $\mathrm{PhD}$ students, postdoctoral researchers and young scientists in the field of virtual engineering and industrial technologies". The project is implemented with the financial support of the Operational Programme Human Resources Development, co-financed by the European Union through the European Social Fund. 


\section{References}

[1] Parthasarathi N.L., Duraiselvam, M., Borah, U., Effect of plasma spraying parameter on wear resistance of $\mathrm{NiCrBSiCFe}$ plasma coatings on austenitic stainless steel at elevated temperatures at various loads, Materials and Design, 36, pp. 141-151, 2012

[2] Parthasarathi, N.L., Duraiselvam, M., High temperature tribological properties of NiCrBSiCFe plasma-sprayed coating on austenitic stainless steel substrate, Journal of Alloys and Compounds, 505, pp. 824-831, 2010

[3] Skulev, H., Malinov, S., Sha, W., Basheer, P.A.M., Microstructural and mechanical properties of nickel-base plasma sprayed coatings on steel and cast iron substrates, Surface \& Coatings Technology, 197, pp. 177-184, 2005

[4] Sidhu, T.S., Prakash, S., Agrawal, R.D., Characterisations of HVOF sprayed NiCrBSi coatings on Ni- and Fe-based superalloys and evaluation of cyclic oxidation behaviour of some Ni-based superalloys in molten salt environment, Thin Solid Films, 515, pp. 95 -105, 2006

[5] Karagöz, M., Islak, S., Buytoz, S., Kurt, B., Microstructural Characteristics of High Velocity Oxygen Fuel (HVOF) sprayed NiCrBSiSiC Composite Coating on a Low Alloy Steel, 6th International Advanced Technologies Symposium (IATS’11), 16-18 May 2011, Elazı̆ğ, Turkey

[6] Navas, C., Colaço, R., de Damborenea, J. \& Vilar, R., Abrasive wear behavior of laser clad and flame sprayed-melted NiCrBSi coatings, Surface \& Coatings Technology, 200, pp. 6854-6862, 2006

[7] Gormez-del Riro, T., Garrido, M.A., Fernarndez, J.E., Cadenas, M., Rodrirguez, J., Influence of the deposition techniques on the mechanical properties and microstructure of NiCrBSi coatings, Journal of materials processing technology, 204, pp. 304-312, 2008

[8] Gonzalez, R., Garca, M.A., Penuelas, I., Cadenas, M., del Rocio Fernandez Ma., Hernandez Battez, A., Felgueroso, D., Microstructural study of NiCrBSi coatings obtained by different processes, Wear, 263, pp. 619-624, 2007

[9] Gonzalez, R., Cadenas M., Fernandez, R., Cortizo, J.L., Rodr'ıguez, E., Wear behaviour of flame sprayed NiCrBSi coating remelted by flame or by laser, Wear, 262, pp. 301-307, 2007

[10] Guoa, C., Zhoua, J., Chena, J., Zhaoa, J., Yua, Y., Zhoua, H., High temperature wear resistance of laser cladding $\mathrm{NiCrBSi}$ and $\mathrm{NiCrBSi} / \mathrm{WC}$ Ni composite coatings, Wear, 270, pp.492-498, 2011

[11] Meng, Q.W., Geng, L., Zhang, B.Y., Laser cladding of Ni-base composite coatings onto $\mathrm{Ti}-6 \mathrm{Al}-4 \mathrm{~V}$ substrates with pre-placed $\mathrm{B} 4 \mathrm{C}+\mathrm{NiCrBSi}$ powders, Surface \& Coatings Technology, 200, pp. 4923-4928, 2006

[12] Tongov, M., Simeonova, T., "Study of the formation of layers produced by high concentrated energy", 11-th International Scientific Conference of the Association Of Machine Technology Faculties in Bulgaria “AMTEH'2012”, Proceedings, ISBN 978-954-438-994-9, pp. 156-165 
[13] Tongov, M., Simeonova, T., Study of the wear-resistance of layers, obtained by plasma melting, IX National Conference on Tribology with International Participation "BULTRIB'2012", Tribological Journal BULTRIB , ISSN 1313-9878 - in press

[14] Zikin, A., Hussainova, I., Katsich, C., Badisch, E., Tomastik, C., Advanced chromium carbide-based hardfacings, Surface \& Coatings Technology, 206, pp. 4270-4278, 2012

[15] Flores, J.F., Neville, A., Kapur, N., Gnanavelu, A., An experimental study of the erosion-corrosion behavior of plasma transferred arc MMCs, Wear, 267, pp. 213-222, 2009

[16] Kesavan, D., Kamaraj, M., The microstructure and high temperature wear performance of a nickel base hardfaced coating, Surface \& Coatings Technology, 204, pp. 4034-4043, 2010

[17] Kesavan, D., Kamaraj, M., Influence of aging treatment on microstructure, wear and corrosion behavior of a nickel base hardfaced coating, Wear, 272, pp. 7-17, 2011

[18] Liyanage, T., Fisher, G., Gerlich, A.P., Influence of alloy chemistry on microstructure and properties in $\mathrm{NiCrBSi}$ overlay coatings deposited by plasma transferred arc welding (PTAW), Surface \& Coatings Technology, 205, pp. 759-765, 2010 